\title{
The physiological basis of pulmonary gas exchange: implications for clinical interpretation of arterial blood gases
}

\author{
Peter D. Wagner \\ Number 8 in the series "Physiology in respiratory medicine" \\ Edited by R. Naeije, D. Chemla, A. Vonk-Noordegraaf and A.T. Dinh-Xuan
}

Affiliation: Dept of Medicine, University of California, San Diego, La Jolla, CA, USA.

Correspondence: Peter D. Wagner, Dept of Medicine, University of California, San Diego, 9500 Gilman Drive, La Jolla, CA 92093, USA. E-mail: pdwagnerQucsd.edu

ABSTRACT The field of pulmonary gas exchange is mature, with the basic principles developed more than 60 years ago. Arterial blood gas measurements (tensions and concentrations of $\mathrm{O}_{2}$ and $\mathrm{CO}_{2}$ ) constitute a mainstay of clinical care to assess the degree of pulmonary gas exchange abnormality. However, the factors that dictate arterial blood gas values are often multifactorial and complex, with six different causes of hypoxaemia (inspiratory hypoxia, hypoventilation, ventilation/perfusion inequality, diffusion limitation, shunting and reduced mixed venous oxygenation) contributing variably to the arterial $\mathrm{O}_{2}$ and $\mathrm{CO}_{2}$ tension in any given patient. Blood gas values are then usually further affected by the body's abilities to compensate for gas exchange disturbances by three tactics (greater $\mathrm{O}_{2}$ extraction, increasing ventilation and increasing cardiac output). This article explains the basic principles of gas exchange in health, mechanisms of altered gas exchange in disease, how the body compensates for abnormal gas exchange, and based on these principles, the tools available to interpret blood gas data and, quantitatively, to best understand the physiological state of each patient. This understanding is important because therapeutic intervention to improve abnormal gas exchange in any given patient needs to be based on the particular physiological mechanisms affecting gas exchange in that patient.

@ERSpublications

Understanding the physiological basis of pulmonary gas exchange can help guide therapeutic approaches to patients http://ow.ly/zNnK5

Received: Feb 262014 | Accepted after revision: July 062014 | First published online: Oct 162014

Previous articles in this series: No. 1: Naeije R, Vachiery J-L, Yerly P, et al. The transpulmonary pressure gradient for the diagnosis of pulmonary vascular diseases. Eur Respir J 2013; 41: 217-223. No. 2: Hughes JMB, van der Lee I. The TL,NO/TL,CO ratio in pulmonary function test interpretation. Eur Respir J 2013; 41: 453-461. No. 3: Vonk-Noordegraaf A, Westerhof N. Describing right ventricular function. Eur Respir J 2013; 41: 1419-1423. No. 4: Hamzaoui O, Monnet X, Teboul J-L. Pulsus paradoxus. Eur Respir J 2013; 42: 1696-1705. No. 5: Prisk GK. Microgravity and the respiratory system. Eur Respir J 2014; 43: 1459-1471. No. 6: Dempsey JA, Smith CA. Pathophysiology of human ventilatory control. Eur Respir J 2014; 44: 495-512. No. 7: Petersson J, Glenny RW. Gas exchange and ventilation-perfusion relationships in the lung. Eur Respir J 2014; 44: 1023-1041.

Conflict of interest: None declared.

Copyright @ERS 2015 


\section{Introduction}

The reason we have a lung is well known: to allow the exchange of gases between the air we breathe and the pulmonary capillary blood. We are primarily concerned with two gases, $\mathrm{O}_{2}$ and $\mathrm{CO}_{2}$, but what follows applies in concept to all gases (that are not chemically reactive with tissues). Moreover, it does not matter whether the gas is being passed from air to blood (e.g. $\left.\mathrm{O}_{2}\right)$ or from blood to gas (e.g. $\left.\mathrm{CO}_{2}\right)$ because the principles governing gas exchange apply equally in both directions. By exchanging gases, the lungs form one critical part of the $\mathrm{O}_{2} / \mathrm{CO}_{2}$ transport pathway (fig. 1), the rest of which involves the entire cardiovascular system (heart, vasculature and blood) as well as the body tissues. The entire system, not just the lungs, needs to be considered when interpreting arterial blood gases because each component may affect the others (see section on causes of hypoxaemia below).

The lungs are a collection of some 300 million very small gas-filled polyhedrons (alveoli), the walls of which are made up of little more than a rich capillary network supported by a very thin interstitial matrix. Each alveolus expands with fresh gas (high in $\mathrm{O}_{2}$ and low in $\mathrm{CO}_{2}$ ) that has flowed down the bronchial tree from the mouth during inspiration. The alveoli then reduce in volume during expiration, returning gas (lower in $\mathrm{O}_{2}$ and higher in $\mathrm{CO}_{2}$ ) up the bronchial tree to the mouth. This process is of course called ventilation. The capillaries in the alveolar wall are fed pulmonary arterial blood returned from the tissues. This blood is low in $\mathrm{O}_{2}$ and high in $\mathrm{CO}_{2}$, but after the blood has flowed through the alveolus and reaches the pulmonary veins, $\mathrm{O}_{2}$ has been raised and $\mathrm{CO}_{2}$ lowered through the gas exchange process. Normally, all alveoli are both ventilated and perfused. While these statements may be self-evident to most, they become the central concept behind how gas exchange occurs and therefore how blood gas numbers can be used clinically.

The structure of the lung has evolved to meet the gas exchange needs on the basis of an overarching, major principle: The exchange of gases between the alveolar gas and the blood occurs by simple, passive diffusion (fig. 1). There is no active transport involved in alveolar gas exchange, and the process of diffusion requires no energy expenditure by the organism. Of course, both ventilation and perfusion are convective processes that do require energy expenditure, and in many common cardiorespiratory diseases, either or both may be compromised.

This article will first explain quantitative aspects of gas exchange based on the above basic principles, starting with the simplest proposition: that of a uniform lung in which all 300 million alveoli are equally perfused and equally ventilated. Real lungs, even in health, are however far from uniform in this regard $[1,2]$, and this heterogeneity has negative consequences for gas exchange that will next be discussed. The multiple possible causes of abnormal gas exchange will then be summarised, and this will lead to a scheme for interpreting gas exchange findings in clinical settings.

Because the principles of gas exchange apply to all non-reactive gases, the focus will be mostly on just one gas, $\mathrm{O}_{2}$. Application to $\mathrm{CO}_{2}$ will also be indicated but without detailed parallel treatment.

\section{Principles of pulmonary gas exchange}

Based on the above, pulmonary gas exchange is considered as a continuous process involving: 1) ventilation, 2) diffusion (including both physical diffusion across the pulmonary blood:gas barrier and

\section{The $\mathrm{O}_{2}$ transport pathway}

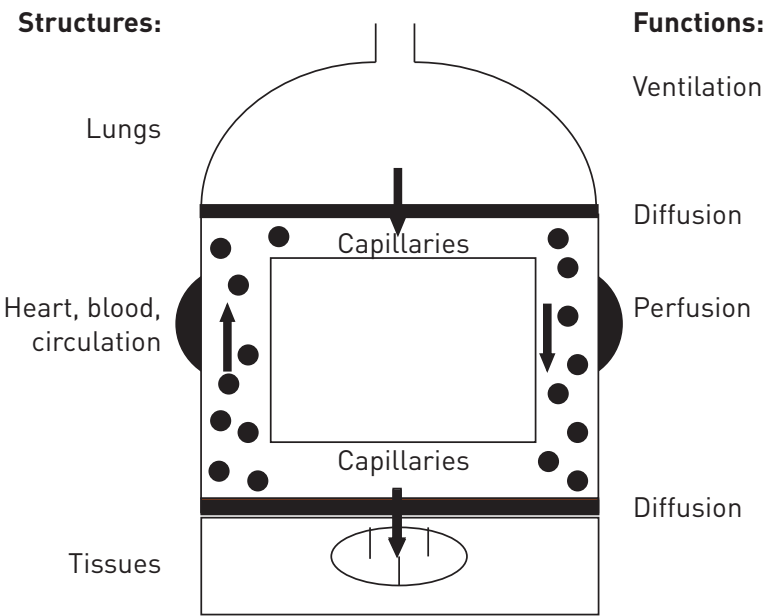

FIGURE 1 Schematic of the $\mathrm{O}_{2}$
transport pathway showing the
principal structures and their
physiological functions. The $\mathrm{CO}_{2}$
transport pathway from the tissues to
the lungs mirrors that for $\mathrm{O}_{2}$.


subsequent chemical reactions (between $\mathrm{O}_{2}$ and haemoglobin $(\mathrm{Hb})$ and for $\mathrm{CO}_{2}$ conversion to bicarbonate), and 3) perfusion. The fundamental principle that brings these three separate physical processes together quantitatively is conservation of mass. All that this means is that within the lungs, every $\mathrm{O}_{2}$ molecule that is inhaled but not exhaled diffuses from alveolar gas to blood and can be found in that blood.

In quantitative terms, the product of minute ventilation $\left(V^{\prime} \mathrm{E}, \mathrm{L} \cdot \mathrm{min}^{-1}\right)$ and the difference between inspired and mixed expired $\mathrm{O}_{2}$ concentrations $\left(\mathrm{FIO}_{2}\right.$ and $\mathrm{FEO}_{2}$ respectively) quantifies the amount of $\mathrm{O}_{2}$ $\left(V^{\prime} \mathrm{O}_{2}\right)$ that leaves the alveolar gas and enters the pulmonary capillary blood per minute. The $\mathrm{O}_{2}$ entering the pulmonary capillaries is quantified by the product of pulmonary blood flow $\left(Q^{\prime}, \mathrm{L} \cdot \mathrm{min}^{-1}\right)$ and the difference between pulmonary venous $\left(\mathrm{CpvO}_{2}\right)$ and pulmonary arterial $\left(\mathrm{C}_{\bar{v}} \mathrm{O}_{2}\right) \mathrm{O}_{2}$ concentrations. In this section, it is assumed, as stated above, that the lungs are homogeneous, such that the concentration of $\mathrm{O}_{2}$ in the blood leaving every alveolus is the same, and, passing unchanged into the systemic arterial blood, is thus equal to the systemic arterial $\mathrm{O}_{2}$ concentration $\left(\mathrm{CaO}_{2}\right)$. This can now all be expressed by the following simple mass conservation equations:

$$
V^{\prime} \mathrm{O}_{2}=V^{\prime} \mathrm{E} \times\left(\mathrm{FIO}_{2}-\mathrm{FEO}_{2}\right)=V^{\prime} \mathrm{A} \times\left(\mathrm{FIO}_{2}-\mathrm{FAO}_{2}\right)
$$

and

$$
V^{\prime} \mathrm{O}_{2}=Q^{\prime} \times\left(\mathrm{CaO}_{2}-\mathrm{C}_{\bar{v}} \mathrm{O}_{2}\right)
$$

In the right hand part of equation 1, it is recognised that the conducting airways do not themselves take part in air/blood gas exchange. This allows minute ventilation and mixed expired $\mathrm{O}_{2}$ concentration to be replaced by alveolar ventilation $\left(V^{\prime} \mathrm{A}\right)$ and alveolar $\mathrm{O}_{2}$ concentration $\left(F_{\mathrm{AO}}\right)$, respectively.

Because the process of diffusional transport described above usually comes to rapid completion well within the red cell transit time (at rest at sea level) [3], the $\mathrm{PO}_{2}$ in the alveolar gas $\left(\mathrm{PAO}_{2}\right)$ and the capillary blood leaving the alveolus can be considered to be the same. This means that $\mathrm{CpvO}_{2}$ (and thus $\mathrm{CaO}_{2}$ in equation 2 ) is that $\mathrm{O}_{2}$ concentration that can simply be read off the $\mathrm{HbO}_{2}$ dissociation curve at the value of $P_{\mathrm{AO}_{2}}$ (noting that $\mathrm{PAO}_{2}=\mathrm{FAO}_{2} \times \mathrm{k}$, where $\mathrm{k}$ is a constant equal to (barometric pressure minus saturated water vapour pressure)/100).

More than 60 years ago, Rahn and Fenn [4] and Riley, Cournand and co-workers [5-7] separately put these equations together noting that both expressed the same variable, $V^{\prime} \mathrm{O}_{2}$ :

$$
V^{\prime} \mathrm{A} \times\left(\mathrm{FIO}_{2}-\mathrm{FAO}_{2}\right)=Q^{\prime} \times\left(\mathrm{CaO}_{2}-\mathrm{C}_{\overline{\mathrm{v}}} \mathrm{O}_{2}\right)
$$

Rearranging the terms gives:

$$
V^{\prime} \mathrm{A} / Q^{\prime}=8.63 \times\left(\mathrm{CaO}_{2}-\mathrm{C}_{\overline{\mathrm{v}}} \mathrm{O}_{2}\right) /\left(\mathrm{PIO}_{2}-\mathrm{PAO}_{2}\right)
$$

Here the constant term harmonises the equation when the units used are $\mathrm{L} \cdot \mathrm{min}^{-1}$ for both $V^{\prime}$ A (BTPS) and $Q^{\prime} ; \mathrm{mL} \cdot \mathrm{dL}^{-1}$ (STPD) for both $\mathrm{CaO}_{2}$ and $\mathrm{C}_{\overline{\mathrm{v}}} \mathrm{O}_{2}$; and $\mathrm{mmHg}$ for both $\mathrm{PIO}_{2}$ and $\mathrm{PAO}_{2}$.

In the preceding, some simplifying assumptions have been made. We do assume ventilation and perfusion are continuous processes, implying blood and gas $\mathrm{O}_{2}$ concentrations are constant in time, thus ignoring the normal, minor fluctuations in alveolar $\mathrm{PO}_{2}$ between inspiration and expiration [8]; we have, for now, assumed the lung is homogenous, with all alveoli having the same $V^{\prime} \mathrm{A} / Q^{\prime}$ ratio; we have assumed that inspired and expired gas volumes are identical, which is true to within 1\%; and we have assumed that the blood leaving the alveoli and entering the pulmonary veins reaches the systemic arteries (where it can be sampled clinically) without change in $\mathrm{O}_{2}$ concentration-hence the "a" in $\mathrm{CaO}_{2}$ to denote arterial blood. Finally, diffusion equilibration has been assumed as mentioned above, allowing $\mathrm{CaO}_{2}$ to be directly calculated from the $\mathrm{HbO}_{2}$ dissociation curve, if $\mathrm{PAO}_{2}$ is known. While all theoretically important, these assumptions are a good way to start understanding gas exchange; if they had to be removed, understanding gas exchange would become an intractable exercise in a short article such as this. Research has shown that in health the numerical effect of their combined considerations is mostly trivial, justifying setting them aside. In disease, heterogeneity of $V^{\prime} \mathrm{A}$ and $Q^{\prime}$ may be severe and then the assumption of homogeneity is invalid, as discussed below.

Equation 4 is telling us this: if we know 1) the $V^{\prime} \mathrm{A} / Q^{\prime}$ ratio in the lung (total alveolar ventilation to total pulmonary blood flow); 2) the composition of inspired gas and pulmonary arterial blood $\left(\mathrm{PIO}_{2}\right.$ and $\mathrm{C}_{\overline{\mathrm{N}}}$ in the equation); and 3) the shape and position of the $\mathrm{HbO}_{2}$ dissociation curve (so we can calculate $\mathrm{CaO}_{2}$ 
from $P_{\mathrm{AO}_{2}}$ ), then there is but one unknown remaining variable in the equation: $P_{\mathrm{AO}_{2}}$. In other words, $P \mathrm{AO}_{2}$ is uniquely determined by the $V^{\prime} \mathrm{A} / Q^{\prime}$ ratio, given the composition of inspired gas and venous blood and the $\mathrm{HbO}_{2}$ dissociation curve particulars. The relationship between $P \mathrm{AO}_{2}$ and $V^{\prime} \mathrm{A} / Q^{\prime}$ derived by solving equation 4 for homogeneous lungs over a wide range of hypothetical $V^{\prime} \mathrm{A} / Q^{\prime}$ ratios is shown in figure 2.

The next step in analysis is that within a given lung, equation 4 can be applied to regions with different $V^{\prime} \mathrm{A} / Q^{\prime}$ ratio, and the results shown in figure 2 still apply, but now to each region, according to that region's $V^{\prime} \mathrm{A} / \mathrm{Q}^{\prime}$ ratio. Also shown in figure 2 are the corresponding results for $\mathrm{CO}_{2}$. Following through the exact same logic presented for $\mathrm{O}_{2}$, the equation for $\mathrm{CO}_{2}$ is:

$$
V^{\prime} \mathrm{A} / Q^{\prime}=8.63 \times\left(\mathrm{C}_{\bar{v}} \mathrm{CO}_{2}-\mathrm{CaCO}_{2}\right) /\left(\mathrm{PACO}_{2}-\mathrm{PICO}_{2}\right)
$$

The terms on the right side for $\mathrm{CO}_{2}$ are reversed (compared to $\mathrm{O}_{2}$ ) only because $\mathrm{CO}_{2}$ is being eliminated from the blood while $\mathrm{O}_{2}$ is being taken up. This keeps both numerator and denominator for equation 5 positive. The curves in figure 2 are different in shape and slope largely because of the different shapes and slopes of the respective dissociation curves of the two gases, and because $\mathrm{O}_{2}$ is taken up while $\mathrm{CO}_{2}$ is eliminated.

Figure 2 is very revealing: When $V^{\prime} \mathrm{A} / Q^{\prime}$ is normal (i.e. about 1), $P \mathrm{AO}_{2}$ is $100 \mathrm{mmHg}$ and $P_{\mathrm{ACO}_{2}} 40 \mathrm{mmHg}$. If a region of lung becomes poorly ventilated, usually due to airway obstruction, but maintains normal perfusion, $V^{\prime} \mathrm{A} / Q^{\prime}$ ratio of that region must be reduced, and $\mathrm{PAO}_{2}$ and blood $\mathrm{O}_{2}$ concentration will fall (and $P_{\mathrm{ACO}_{2}}$ rise, but by only a small amount). Conversely, as $V^{\prime} \mathrm{A} / Q^{\prime}$ rises in a lung region, often due to vascular obstruction, $\mathrm{PAO}_{2}$ rises while $\mathrm{PACO}_{2}$ falls. Because of the differences in the respective dissociation curves, $\mathrm{O}_{2}$ concentration rises only little, but $\mathrm{PACO}_{2}$ and $\mathrm{CO}_{2}$ concentration fall considerably. This is a profound conclusion: when low $V^{\prime} \mathrm{A} / Q^{\prime}$ ratio regions exist, $\mathrm{O}_{2}$ is seriously affected, more so than $\mathrm{CO}_{2}$, but when high $V^{\prime} \mathrm{A} / Q^{\prime}$ ratio areas develop, $\mathrm{CO}_{2}$ is the more affected gas.

The alveolar gas equation

The equation for $\mathrm{CO}_{2}$ corresponding to that for equation 1 for $\mathrm{O}_{2}$ is now presented:

$$
V^{\prime} \mathrm{CO}_{2}=V^{\prime} \mathrm{A} \times\left(\mathrm{FACO}_{2}-F \mathrm{ICO}_{2}\right)
$$

If equation 6 is simply divided by equation 1, and ignoring $\mathrm{FICO}_{2}$ as negligible, we get:

$$
V^{\prime} \mathrm{CO}_{2} / V^{\prime} \mathrm{O}_{2}=\mathrm{R}=\mathrm{FACO}_{2} /\left(\mathrm{FIO}_{2}-\mathrm{FAO}_{2}\right)=\mathrm{PACO}_{2} /\left(\mathrm{PIO}_{2}-\mathrm{PAO}_{2}\right)
$$

Here $\mathrm{R}$ is by definition the respiratory exchange ratio, and the change from fractional concentration $(F)$ to partial pressure $(P)$ follows Dalton's law of partial pressures. If we now rearrange equation 7 we have:

$$
\mathrm{PAO}_{2}=\mathrm{PIO}_{2}-\mathrm{PACO}_{2} / \mathrm{R}
$$

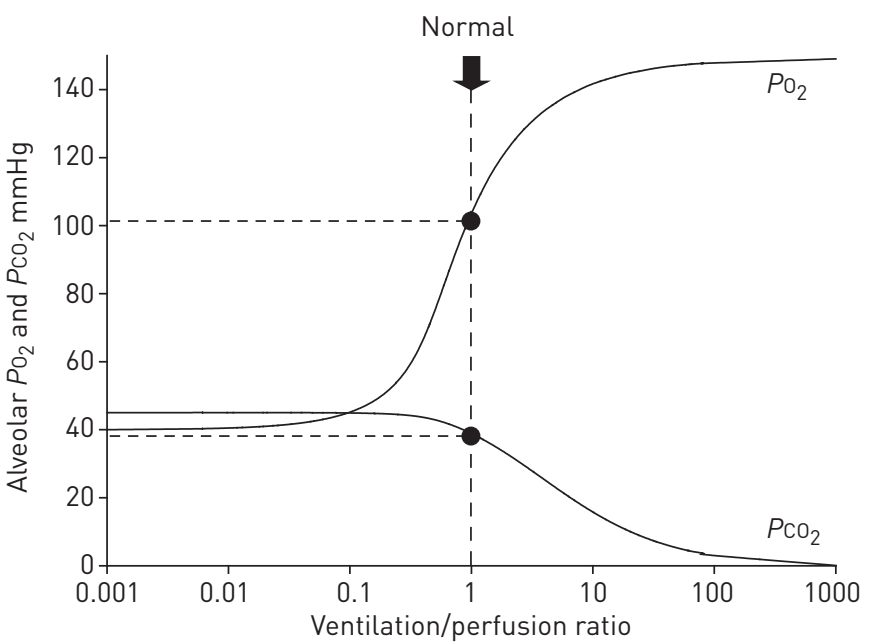

FIGURE 2 Alveolar oxygen and carbon dioxide partial pressures $\left(\mathrm{PO}_{2}\right.$ and $\left.\mathrm{PCO}_{2}\right)$ in homogeneous regions having the alveolar ventilation/perfusion ratio indicated on the abscissa. The curves represent the solutions to equations 4 $\left(\mathrm{O}_{2}\right)$ and $5\left(\mathrm{CO}_{2}\right)$. 
This is the simple form of the well-known alveolar gas equation that relates alveolar $\mathrm{PO}_{2}$ to alveolar $\mathrm{PCO}_{2}$. If one wishes to be accurate and eliminate the assumption that the inspired and expired ventilation values are identical, it can be shown that equation 8 is modified [4]:

$$
P_{\mathrm{AO}_{2}}=P \mathrm{IO}_{2}-P \mathrm{ACO}_{2} / \mathrm{R}+P \mathrm{ACO}_{2} \times F \mathrm{IO}_{2} \times(1-\mathrm{R}) / \mathrm{R}
$$

We will return to the application and use of this equation in the last section of this article.

Arterial $\mathrm{PCO}_{2}$ is of course also used, in conjunction with arterial $\mathrm{pH}$, for analysis of blood acid:base balance. That is itself a large and very important topic and will not be addressed in this article, being beyond its scope.

\section{Ventilation/perfusion inequality}

Even the normal lung is not homogeneous with respect to ventilation and perfusion of all 300 million alveoli $[1,2]$. The amount of inequality can be described by the dispersion of the frequency distribution of $V^{\prime} \mathrm{A} / Q^{\prime}$ ratios (called LOG SDQ), a number akin to the standard deviation of a normal distribution [9]. What does heterogeneity do to gas exchange? Inequality in the distribution of $V^{\prime} \mathrm{A}, Q^{\prime}$ and $V^{\prime} \mathrm{A} / Q^{\prime}$ impairs gas exchange [9]. Figure 3a shows how increasing inequality (i.e. dispersion) will affect arterial $\mathrm{PO}_{2}$, arterial $P_{C O}, \mathrm{O}_{2}$ uptake $\left(V^{\prime} \mathrm{O}_{2}\right), \mathrm{CO}_{2}$ elimination $\left(V^{\prime} \mathrm{CO}_{2}\right)$ and the alveolar-arterial $P_{\mathrm{O}_{2}}$ difference $\left(P \mathrm{~A}-\mathrm{aO}{ }_{2}\right.$, see below). Arterial $\mathrm{PO}_{2}$ will fall; arterial $\mathrm{PCO}_{2}$ and $P \mathrm{~A}-\mathrm{aO} \mathrm{O}_{2}$ will rise (solid lines); $V^{\prime} \mathrm{O}_{2}$ and $V^{\prime} \mathrm{CO}_{2}$ will fall (dashed lines), all compared to the perfect lung with no inequality. The calculations shown in the top panel reflect gas exchange before there has been any change in the $\mathrm{O}_{2}$ and $\mathrm{CO}_{2}$ levels of the venous blood returning to the lungs. However, as arterial $\mathrm{PO}_{2}$ falls and $\mathrm{PCO}_{2}$ rises, the tissues will immediately continue to extract the $\mathrm{O}_{2}$ they need and produce the corresponding $\mathrm{CO}_{2}$. This in turn results in a rapid fall in venous $\mathrm{PO}_{2}$ and rise in venous $\mathrm{PCO}_{2}$, and this will then cause a further fall in arterial $\mathrm{PO}_{2}$ (and increase in arterial $\mathrm{PCO}_{2}$ ). These changes do however allow $V^{\prime} \mathrm{O}_{2}$ and $V^{\prime} \mathrm{CO}_{2}$ to be restored to normal, and are shown in figure $3 \mathrm{~b}$. The calculations are based on well-established computer algorithms that solve the preceding equations for many different values of $V^{\prime} \mathrm{A} / \mathrm{Q}^{\prime}$ ratio and sum up their effects according to how much dispersion is introduced [9]. Figure 3 reveals that both $\mathrm{O}_{2}$ and $\mathrm{CO}_{2}$ are affected by $V^{\prime} \mathrm{A} / Q^{\prime}$ inequality even if the numerical changes are different for the two gases (differences attributable to the different shape and slope of their dissociation curves). The figure also demonstrates the broader principle of how mass transport can be normalised in the face of disease, but at a price. Here, mass transport of $\mathrm{O}_{2}$ and $\mathrm{CO}_{2}$ can be restored, the price being more severe hypoxaemia and hypercapnia (comparing figure $3 \mathrm{a}$ and $\mathrm{b}$ ). This is much like the elevation of blood urea in chronic renal failure, where daily urea excretion by the kidney can be maintained, but the cost is a high blood urea level.

It does not matter whether the cause of the increased $V^{\prime} \mathrm{A} / Q^{\prime}$ ratio dispersion is regional airway obstruction or regional vascular obstruction: the changes from normal will always be in the same direction. However, if the primary lesion is airway obstruction, $\mathrm{O}_{2}$ will be affected more than will $\mathrm{CO}_{2}$, while the reverse holds when vascular obstruction is the primary pathology (as explained above in reference to figure 2).

\section{Compensatory processes}

If $V^{\prime} \mathrm{A} / Q^{\prime}$ inequality develops from disease, and pulmonary uptake of $\mathrm{O}_{2}$ (and elimination of $\mathrm{CO}_{2}$ ) are reduced as above, the tissues will not be able to sustain metabolic rate and if the problem is severe, death will ensue unless the body finds a way to compensate. It is critical to understand the existence and importance of the three innate compensatory processes available to the organism to enable restoration of $\mathrm{O}_{2}$ and $\mathrm{CO}_{2}$ transport between lungs and tissues under such circumstances.

The first process is for the tissues to simply extract more $\mathrm{O}_{2}$ from the blood they receive to restore $\mathrm{O}_{2}$ flux. Since $V^{\prime} \mathrm{A} / Q^{\prime}$ inequality increases $P_{C_{2}}$ in the arterial blood that reaches the tissues, $P_{C_{2}}$ in the tissues will increase as $\mathrm{CO}_{2}$ continues to be produced, and thus the venous $P_{\mathrm{CO}_{2}}$ returning to the lungs will also be higher than normal, again returning $\mathrm{CO}_{2}$ elimination towards normal. These changes in $\mathrm{O}_{2}$ and $\mathrm{CO}_{2}$ are both very rapid, passive, diffusive processes and will occur automatically, before the patient is seen by a clinician. Because blood returns from the tissues with its $\mathrm{Hb}$ normally still $75 \%$ saturated with $\mathrm{O}_{2}$, it contains a lot of $\mathrm{O}_{2}$ that is not normally required, and which can be used to support metabolism. This simple strategy is often very effective. This may well be all that is required to restore $V^{\prime} \mathrm{O}_{2}$ to normal even as the $V^{\prime} \mathrm{A} / Q^{\prime}$ problem remains. The price paid is a more severe drop in arterial $P_{\mathrm{O}_{2}}$, as one would predict from equation 4 and as shown in figure 3.

The second available process is to increase ventilation $\left(V^{\prime} \mathrm{A}\right)$. As ventilation is increased, $V^{\prime} \mathrm{A} / \mathrm{Q}^{\prime}$ ratios throughout the lungs will also be raised, raising $P_{A O}$ and hence also arterial $P_{\mathrm{O}_{2}}$. At the same time, 
a) Mixed venous $\mathrm{PO}_{2}, \mathrm{PCO}_{2}$ constant; $\mathrm{V}_{2} \mathrm{O}_{2}, \mathrm{~V}^{\prime} \mathrm{CO}_{2}$ fall

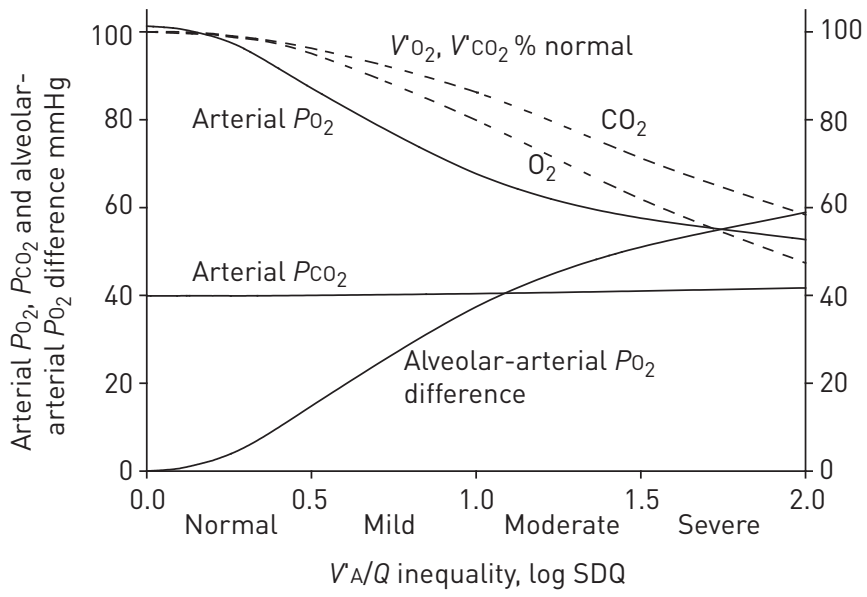

b)

b) $\quad$ Mixed venous $\mathrm{PO}_{2}$ falls, $\mathrm{PCO}_{2}$ rises; $\mathrm{VO}_{2}, \mathrm{~V}^{\prime} \mathrm{CO}_{2}$ maintained

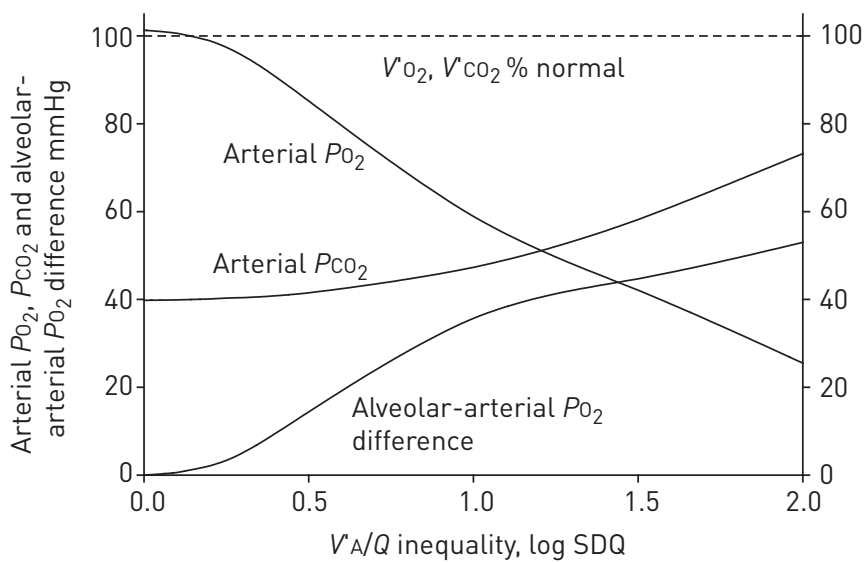

FIGURE 3 Arterial oxygen partial pressure $\left(\mathrm{PO}_{2}\right)$ falls and alveolar-arterial $\mathrm{PO}_{2}$ difference rises as the degree of alveolar ventilation/perfusion $\left(V^{\prime} \mathrm{A} / \mathrm{Q}^{\prime}\right)$ inequality (LOG SDQ, the second moment of the $V^{\prime} \mathrm{A} / \mathrm{Q}^{\prime}$ distribution $(\log$ scale)) becomes more severe. Normal subjects have LOG SDQ values between 0.3 and 0.6. Patients with chronic obstructive pulmonary disease or asthma will usually have values around 1.0, while patients with acute lung injury in the intensive care unit usually have values between 1.5 and 2.5. a) The effects of $V^{\prime} \mathrm{A} / \mathrm{Q}^{\prime}$ inequality prior to any fall in mixed venous (pulmonary arterial) $\mathrm{PO}_{2}$ or rise in mixed venous $\mathrm{PCO}_{2}: \mathrm{O}_{2}$ uptake and $\mathrm{CO}_{2}$ elimination are reduced. b) The same variables are reflected when mixed venous $\mathrm{PO}_{2}$ falls and $\mathrm{PCO}_{2}$ rises, which normalises $\mathrm{O}_{2}$ uptake and $\mathrm{CO}_{2}$ elimination: there is, however, more severe hypoxaemia and hypercapnia as a consequence.

$\mathrm{PACO}_{2}$, and thus arterial $\mathrm{PCO}_{2}$, will be reduced. This compensatory process is also common, and in the absence of airway obstruction, can be very effective. Hyperventilation is especially effective in returning arterial $\mathrm{PCO}_{2}$ to normal (or even subnormal) because of the almost linear shape of the $\mathrm{CO}_{2}$ dissociation curve. In contrast, it is usually less effective in mitigating the fall in arterial $\mathrm{PO}_{2}$ due to the non-linear shape of the $\mathrm{HbO}_{2}$ dissociation curve. In patients with airways obstruction (e.g. chronic obstructive pulmonary disease (COPD) and asthma) the effect on work of breathing and thus shortness of breath can be considerable, and distressing to the patient. Furthermore, persistent obstruction will not materially raise ventilation, or thus alveolar $\mathrm{PO}_{2}$, in the alveoli distal to the obstruction, and this combines with the non-linear shape of the $\mathrm{O}_{2}$ dissociation curve in limiting the gains in arterial $P_{\mathrm{O}_{2}}$ from increased overall ventilation.

The third available process is to increase cardiac output. This mitigates the fall in arterial $\mathrm{PO}_{2}$ because it allows less $\mathrm{O}_{2}$ extraction in the issues (i.e. allows, via equation 2, a higher venous $\mathrm{O}_{2}$ concentration) thereby raising the $\mathrm{PO}_{2}$ in the venous blood returning to the lungs, and as a result, raising arterial $\mathrm{PO}_{2}$, via equation 4. Even if overall and regional ratios of $V^{\prime} \mathrm{A} / Q^{\prime}$ fall as a result of the increase in $Q^{\prime}$, the net result is beneficial to arterial $\mathrm{PO}_{2}$. In the absence of cardiac disease, this can be an effective compensatory process, and is often observed in younger asthmatics who show sympathetic activation either from anxiety, sympathomimetic drugs, or both. This compensatory tactic will also work to reduce venous $\mathrm{PCO}_{2}$ towards normal which, in turn, helps normalise arterial $\mathrm{PCO}_{2}$. 


\section{Causes of arterial hypoxaemia and hypercapnia}

Armed with all of the above information, we can now lay out the possible causes of a reduction in arterial $\mathrm{PO}_{2}$ (i.e. arterial hypoxaemia) and increase in arterial $\mathrm{PCO}_{2}$ (i.e. arterial hypercapnia). The statements that follow assume that there have been no compensatory mechanisms brought into play in each case.

1) Reduced inspired $\mathrm{PO}_{2}$ (going to altitude, aircraft travel (where cabin altitudes are commonly equivalent to around 6000-8000 feet). This will not cause hypercapnia; indeed, ventilatory stimulation from hypoxia will reduce arterial $\mathrm{PCO}_{2}$. However, should inspired $\mathrm{PCO}_{2}$ be increased for any reason, arterial hypercapnia will occur.

2) Overall hypoventilation. This will cause both arterial hypoxaemia and hypercapnia.

3) Ventilation/perfusion $\left(V^{\prime} \mathrm{A} / Q^{\prime}\right)$ inequality. This will cause both arterial hypoxaemia and hypercapnia.

4) Diffusion limitation across the alveolar blood:gas barrier. While a common cause of hypoxaemia in exercise and at altitude even in health, it is uncommon in disease, and to date, diffusion limitation has not been found to affect overall $\mathrm{CO}_{2}$ exchange.

5) Shunting (the flow of blood from right to left sides of the heart without ever seeing alveolar gas). While often causing profound hypoxaemia, hypercapnia can also occur when shunting is massive.

6) Reduction in pulmonary arterial $\mathrm{PO}_{2}$ (seen when $Q^{\prime}$ is low in relation to $V^{\prime} \mathrm{O}_{2}$ ). This will cause hypoxaemia in lungs with $V^{\prime} \mathrm{A} / Q^{\prime}$ inequality. Correspondingly, an increase in pulmonary arterial $P_{\mathrm{CO}_{2}}$ will cause arterial hypercapnia.

Cause 1: reduced inspired $\mathrm{PO}_{2}$

With the fall in barometric pressure with altitude, inspired $\mathrm{PO}_{2}\left(\mathrm{PIO}_{2}\right)$ falls even as the fractional $\mathrm{O}_{2}$ concentration remains constant at about 0.21 . The alveolar gas equation (equation 8 ) is very useful for understanding the quantitative consequences, and shows that $\mathrm{PAO}_{2}$ will fall exactly as much as $\mathrm{PIO}_{2}$ as the latter is reduced, if $\mathrm{PCO}_{2}$ and $\mathrm{R}$ stay constant. In reality, $\mathrm{PAO}_{2}$ will not decrease as much as $\mathrm{PIO}_{2}$ because of hypoxic ventilatory stimulation. The resulting hyperventilation causes $\mathrm{PCO}_{2}$ to fall and $\mathrm{PO}_{2}$ to rise, as shown in figure 4, reproduced from the 1955 monograph by RAHN and FENN "A graphical analysis of the respiratory gas exchange" [4]. Normal values for arterial $\mathrm{PO}_{2}$ at altitude need to take hyperventilation, which increases with increasing altitude, into account, and should not simply be estimated as $P_{\mathrm{AO}_{2}}$ in equation 8 assuming $\mathrm{PCO}_{2}$ is unchanged.

An increase in inspired $P_{C_{2}}$ will raise alveolar $P_{C_{2}}$ at any given value of $V^{\prime} \mathrm{A} / Q^{\prime}$ ratio (equation 5), and thus arterial $\mathrm{PCO}_{2}$. Increased inspired $\mathrm{PCO}_{2}$ is generally not encountered clinically except for accidental exposures, but may be purposefully imposed in research studies.

FIGURE 4 Alveolar oxygen and carbon dioxide partial pressures $\left(\mathrm{PO}_{2}\right.$ and $\left.\mathrm{PCO}_{2}\right)$ measured in normal subjects with acute and chronic altitude exposure. Hypoxia-driven hyperventilation reduces $\mathrm{PCO}_{2}$ and raises $\mathrm{PO}_{2}$ compared to sea levels values as shown. Reproduced with permission from the publisher [4].

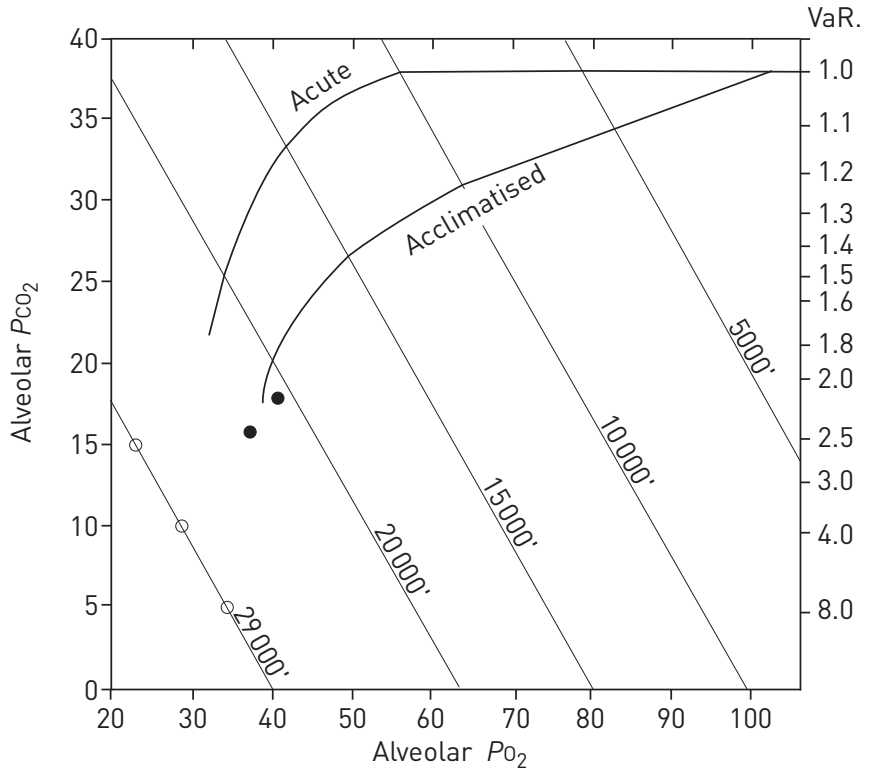




\section{Cause 2: overall hypoventilation}

Overall hypoventilation (reduced alveolar ventilation, $V^{\prime} \mathrm{A}$ ) in a patient with normal lungs can occur under many conditions such as after narcotic drug overdose, in states of severe muscle weakness, or in traumatic injury to any portion of the respiratory system. It commonly is accompanied by additional causes of hypoxaemia (especially 3 and 5 below), but will be discussed here assuming it is the only abnormality present. Equations 1 (for $\mathrm{O}_{2}$ ) and 6 (for $\mathrm{CO}_{2}$ ) show how maintaining metabolic rate in the face of a fall in $V^{\prime}$ A has major effects on alveolar $\mathrm{PO}_{2}$ (which falls) and $\mathrm{PCO}_{2}$ (which rises, such that absence of hypercapnia excludes hypoventilation). Figure 5 shows these effects quantitatively. Normal resting alveolar ventilation is about $5 \mathrm{~L} \cdot \mathrm{min}^{-1}$. The important point is that as $V^{\prime} \mathrm{A}$ falls even modestly, the effects will be dramatic for both $\mathrm{O}_{2}$ and $\mathrm{CO}_{2}$. Because in this example the lungs are assumed to remain normal, the alveolar arterial difference calculated from the alveolar gas equation (equation 8) remains normal.

\section{Cause 3: ventilation/perfusion inequality}

$V^{\prime} \mathrm{A} / Q^{\prime}$ inequality occurs normally, but this is of minimal clinical importance as a cause of arterial hypoxaemia: arterial $\mathrm{PO}_{2}$ (at sea level) is usually above $90 \mathrm{mmHg}$ in normal subjects. However, in cardiopulmonary diseases, $V^{\prime} \mathrm{A} / \mathrm{Q}^{\prime}$ inequality can be severe, and lead to very low arterial $\mathrm{PO}_{2}$ values (fig. 3). It may be severe enough to be fatal. Essentially all lung diseases cause significant $V^{\prime} \mathrm{A} / Q^{\prime}$ inequality, although the physiological and structural mechanisms can be extremely variable from disease to disease. Inequality affects $\mathrm{PO}_{2}$ no matter whether the primary pathology resides in the blood vessels, the parenchymal tissues, or the airways.

It is very important to recognise that $V^{\prime} \mathrm{A} / Q^{\prime}$ inequality impairs the exchange of all gases, not just that of $\mathrm{O}_{2}$. Thus, in addition to hypoxaemia, arterial hypercapnia will always be an initial result of $V^{\prime} \mathrm{A} / Q^{\prime}$ inequality. That said, when arterial blood gases are measured in patients with $V^{\prime} \mathrm{A} / Q^{\prime}$ inequality, arterial $\mathrm{PCO}_{2}$ may be normal or even below normal. This apparent contradiction is easily understood if the degree of compensatory hyperventilation (see above) is taken into account. Because of differences in the shapes and slopes of their dissociation curves, $\mathrm{O}_{2}$ and $\mathrm{CO}_{2}$ tensions in blood will respond quite differently to both the initial $V^{\prime} \mathrm{A} / Q^{\prime}$ inequality and to subsequent ventilatory compensation. Arterial $\mathrm{PO}_{2}$ usually falls much more than does $P_{C}$ rise when $V^{\prime} \mathrm{A} / Q^{\prime}$ inequality develops. In addition, arterial $P_{C_{2}}$ is often normalised by even small compensatory increases in ventilation, but this is not the case for $\mathrm{O}_{2}$, where the increase in $\mathrm{PO}_{2}$ is usually more modest. As a result, $V^{\prime} \mathrm{A} / Q^{\prime}$ inequality essentially always results in hypoxaemia, although arterial $\mathrm{PCO}_{2}$ can be high, normal or low, depending on the amount of compensatory hyperventilation.

A final important point about $V^{\prime} \mathrm{A} / Q^{\prime}$ inequality is that while it causes significant hypoxaemia breathing room air, arterial $\mathrm{PO}_{2}$ increases to levels seen in normal subjects when $100 \% \mathrm{O}_{2}$ is breathed. This is because, given enough time (it may take $10-30 \mathrm{~min}$ ), $100 \% \mathrm{O}_{2}$ breathing washes out all alveolar nitrogen, leaving only $\mathrm{O}_{2}$ and $\mathrm{CO}_{2}$ in the alveolar gas. This means that even in poorly ventilated regions, alveolar $\mathrm{PO}_{2}$ will rise to above $600 \mathrm{mmHg}$, just as in normally ventilated regions.

\section{Cause 4: diffusion limitation}

As stated, all gases exchange between alveolar gas and pulmonary capillary blood by passive diffusion. Factors that affect the diffusional conductance of a gas include the thickness of the blood:gas barrier, the overall alveolar-capillary contact surface area, the solubility of the gas in the haemoglobin-free blood:gas

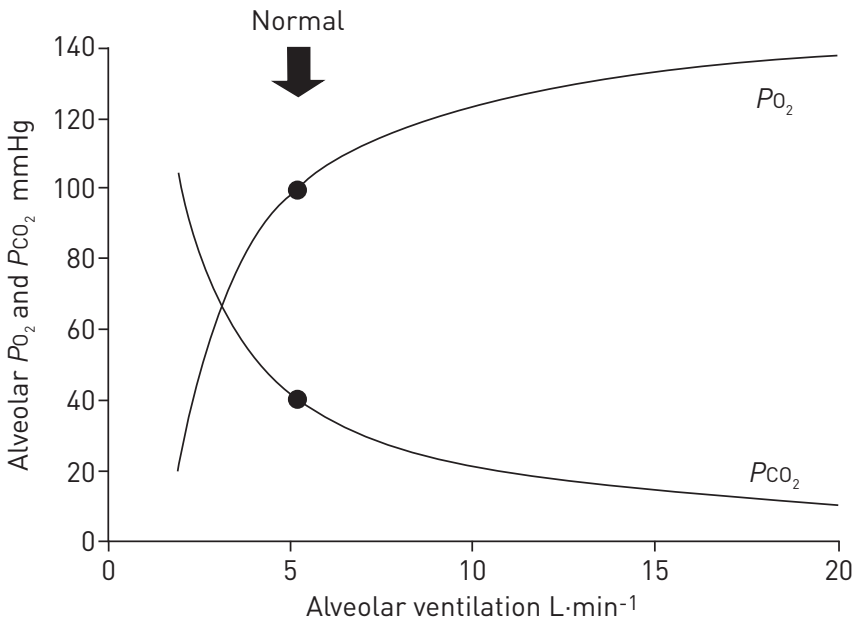

FIGURE 5 Alveolar partial pressure of oxygen $\left(\mathrm{PO}_{2}\right)$ (from solving equation 1 ) and $\mathrm{PCO}_{2}$ (from equation 6) as a function of alveolar ventilation in a normal lung. Note how sensitive both $\mathrm{PO}_{2}$ and $\mathrm{PCO}_{2}$ are to small decreases in ventilation. 
barrier, and the molecular weight of the gas. Additional factors that affect the completeness with which diffusion equilibration occurs in the alveolar microcirculation include the rate of reaction between the gas and haemoglobin (for gases such as $\mathrm{O}_{2}, \mathrm{CO}$ and $\mathrm{CO}_{2}$ ), the capacity of haemoglobin to carry the gas, and the time a red cell spends in the pulmonary microcirculation exchanging gas. This transit time in turn reflects the ratio of microcirculatory blood volume to blood flow.

This multitude of contributing factors can be brought into a single unifying concept, as shown by PIIPER and Scheid [10] several years ago. The degree of diffusion equilibration (that is, how close to alveolar partial pressure the blood partial pressure comes by the end of the capillary transit) depends on the ratio of diffusing capacity $(D \mathrm{~L})$ to the product of blood flow $\left(Q^{\prime}\right)$ and $\beta$; that is, to $D L /\left(\beta Q^{\prime}\right)$. Here, $\beta$ is the overall "solubility" of the gas in blood. For $\mathrm{O}_{2}$ it is approximated by the ratio of arterial-mixed venous $\mathrm{O}_{2}$ concentration difference to arterial-mixed venous $\mathrm{PO}_{2}$ difference, which indicates the average slope of the $\mathrm{O}_{2}$ dissociation curve. This compound number intrinsically incorporates transit time and capillary volume, as can be seen when one writes down and solves the diffusion equation [10].

In health, at rest at sea level, the red cell requires only about $0.25 \mathrm{~s}$ for equilibration-that is, for red cell $\mathrm{PO}_{2}$ to rise from pulmonary arterial to alveolar values [3]. The available transit time is about $0.75 \mathrm{~s}$, implying a three-fold reserve in time available. Failure of equilibration is, therefore, not seen in healthy subjects at rest, and this remains so at rest even at altitude. However, during exercise at sea level, failure of equilibration is frequently (but not universally) observed, especially in athletes who have high rates of blood flow and thus lower red cell transit times. At altitude, exercise results in failure of equilibration in essentially everyone [11]. This is due to the reduced $\mathrm{PO}_{2}$ diffusion gradient stemming from inspiratory hypoxia, especially combined with reduced transit time [12].

In lung diseases, failure of diffusional equilibration is rarely seen. It appears to be consistently measureable only in patients with interstitial lung diseases [13] and is seen most often when they exercise. It is seen at rest only in severe cases of interstitial lung disease when lung function is at $50 \%$ of normal or less. It may be a factor contributing to the hypoxaemia in rarer conditions associated with pulmonary arterio-venous malformations and/or vascular dilatation, the most common of which may be cirrhosis of the liver. Here the possibility is that the long intravascular distances $\mathrm{O}_{2}$ must travel to reach all flowing red cells prevent complete diffusion equilibration within the red cell transit time. The reader is referred to the review by RoDRIGUEZ-ROISIN and KROWKa [14] for a more detailed discussion of this topic. It has not been found to happen in COPD [15], asthma [16], pulmonary thromboembolic disease [17] or in the critically ill.

Diffusion limitation of $\mathrm{CO}_{2}$ has not so far been documented. The diffusing capacity of $\mathrm{CO}_{2}$ across the blood:gas barrier (quantity of $\mathrm{CO}_{2}$ transported per minute per $\mathrm{mmHg}$ partial pressure difference across that barrier) is much greater than for $\mathrm{O}_{2}$. This is because of the approximately 20 -fold greater physical solubility of $\mathrm{CO}_{2}$ in the blood gas barrier. However, the capacity of the blood to hold $\mathrm{CO}_{2}$ (as bicarbonate, dissolved $\mathrm{CO}_{2}$ and carbamino- $\mathrm{Hb}$ ), per $\mathrm{mmHg} \mathrm{PCO}_{2}$, is approximately 10 -fold greater than that of blood to hold $\mathrm{O}_{2}$ (per $\mathrm{mmHg} \mathrm{PO}_{2}$ ). This acts to partly counterbalance the higher barrier solubility just mentioned such that the time to equilibration for $\mathrm{CO}_{2}$ is not 20 times less than for $\mathrm{O}_{2}$ but more like only two-fold less. Even considering that the chemical reaction steps whereby $\mathrm{CO}_{2}$ is converted to bicarbonate inside the red cell, followed by exchange of bicarbonate for chloride, are relatively slow (half-time calculated to be about $0.1 \mathrm{~s}$ ), $\mathrm{CO}_{2}$ appears to equilibrate faster than does $\mathrm{O}_{2}$.

\section{Cause 5: shunting}

Shunting is defined as blood passing from right to left sides of the heart without ever seeing alveolar gas. This can be through cardiac shunts (atrial, ventricular), in congenital heart diseases, and in lung diseases associated with atelectasis or alveolar filling with fluid or cell debris. It may also occur in lung diseases associated with large arterio-venous connections, such as cirrhosis and hereditary haemorrhagic telangiectasia [14]. Research has shown that most patients with chronic lung diseases such as COPD and asthma have little if any shunting $[15,16]$, but that patients with acute lung diseases (pneumonias, acute lung injury, respiratory distress syndromes) typically do have shunts, that can sometimes be severe [18, 19].

Arterial $\mathrm{PO}_{2}$ is usually not very responsive to increases in $\mathrm{FIO}_{2}$ in such patients (in contrast to what is seen with $V^{\prime} \mathrm{A} / Q^{\prime}$ inequality, see above). Thus, shunting is best quantified while the patient breathes $100 \% \mathrm{O}_{2}$ in order to eliminate contributions from, and confusion with, $V^{\prime} \mathrm{A} / Q^{\prime}$ inequality that usually co-exists with shunting, and diffusion limitation, if present.

While the effects of shunting on arterial $\mathrm{PO}_{2}$ are dramatic and well-known, shunting can also affect arterial $\mathrm{PCO}_{2}$ (and, as mentioned in the introduction, the exchange of all gases). Arterial $\mathrm{PCO}_{2}$ will increase when shunts develop (unless compensated by hyperventilation as commonly occurs). This is because shunted blood, carrying $\mathrm{CO}_{2}$ at high pulmonary arterial levels, mixes with non-shunted blood to form systemic 
arterial blood. Small to moderate shunts of $20 \%$ or less raise arterial $\mathrm{PCO}_{2}$ by only a mmHg or two, but the relationship between shunt fraction and arterial $\mathrm{PCO}_{2}$ is quite nonlinear, and when shunt is very high, 40$50 \%$ of the cardiac output, arterial $\mathrm{PCO}_{2}$ can rise by more than $10 \mathrm{mmHg}$ (again, in the absence of ventilatory compensation).

\section{Cause 6: reduction in pulmonary arterial $\mathrm{PO}_{2}\left(\mathrm{P}_{\bar{v}} \mathrm{O}_{2}\right)$}

This factor was mentioned above in discussing cardiac output as a potential compensating factor reversing arterial hypoxaemia. At the outset it should be mentioned that there is an exception to the rule that a fall in $P_{\overline{\mathrm{v}}} \mathrm{O}_{2}$ will cause a fall in arterial $\mathrm{PO}_{2}$ : the perfectly homogeneous lung. In this case, $P_{\mathrm{AO}_{2}}$ is governed by having to fulfil the conditions of equation 1 above, making it dependent only on $V^{\prime} \mathrm{O}_{2}, V^{\prime} \mathrm{A}$ and $\mathrm{FIO}_{2}$ (and thus not on $P_{\overline{\mathrm{v}}} \mathrm{O}_{2}$ ). Because the lung is homogeneous, $\mathrm{PaO}_{2}$ must equal $P_{\mathrm{AO}}$ and is thus also unaffected by changes in $P_{\overline{\mathrm{v}}} \mathrm{O}_{2}$. Reduction in pulmonary arterial $\mathrm{P}_{2}$ may however better be thought of as an extrapulmonary modifier of arterial $\mathrm{PO}_{2}$. It comes into play when $Q^{\prime}$ is low in relation to $V^{\prime} \mathrm{O}_{2}$ (equation 2), thereby reducing $P_{\overline{\mathrm{v}}} \mathrm{O}_{2}$. Its effect is evident from equation 4. Thus, if $P_{\overline{\mathrm{v}}} \mathrm{O}_{2}$ falls, so too will $P_{\mathrm{AO}_{2}}$, and thus arterial $\mathrm{PO}_{2}$ will also fall. Figure 3, described earlier, exemplifies this effect (compare $\mathrm{PaO}_{2}$ between figure $3 \mathrm{a}$ and $\mathrm{b}$ ), and further shows the effects are greater the more $V^{\prime} \mathrm{A} / Q^{\prime}$ inequality there is. It is especially important to understand this cause in the critically ill patient receiving inspired gas high in $\mathrm{O}_{2}$. Arterial $\mathrm{PO}_{2}$ in such a patient may change considerably without change in lung function (causes 2-5 above) or in $\mathrm{PIO}_{2}$ (cause 1 above) if cardiac output changes in relation to metabolic rate. This is shown in figure 6. Distinguishing the causes of change in arterial $\mathrm{PO}_{2}$ is of obvious therapeutic importance in such circumstances.

In a corresponding manner, if $Q^{\prime}$ is low in relation to $V^{\prime} \mathrm{CO}_{2}$, pulmonary arterial $\mathrm{PCO}_{2}$ must rise, and in the face of unchanged ventilation, must cause alveolar and thus arterial $\mathrm{PCO}_{2}$ to increase.

Importantly, many of the above causes may coexist in a given patient, which can result in complex blood gas presentations that can be difficult to unravel in the clinical setting, especially when limited measurements are made.

\section{Assessment and interpretation of arterial blood gases}

An orderly, systematic, multi-level approach is recommended, based on the preceding physiological discussion, perhaps as laid out below. Just how detailed one needs to get (how many levels to pursue) will depend on the clinical questions at hand; one should ask for what purpose was the blood gas sample obtained? What was the clinical question that needs to be answered? The suggested system is a physiologically based construct, and is not designed to provide pathogenetic diagnosis of any particular disease state. In other words, it is limited to providing quantitative assessment of the severity of gas exchange disturbances, and the physiological factors underlying them. The levels proceed from the simplest to more complex, and, past level 1, require either additional measurements or making assumptions that may or may not be valid in any given situation. As stated previously, the acid/base component of arterial blood gas analysis (involving $\mathrm{pH}-\mathrm{PCO}_{2}$ relationships) is beyond the scope of this article and is not addressed.

The minimal requirement is an arterial blood gas sample in which the $\mathrm{PO}_{2}, \mathrm{PCO}_{2}, \mathrm{pH}$, haemoglobin level and $\mathrm{O}_{2}$ saturation have been measured, although additional measurements will be necessary for some of the derived indices described below (indicated in the appropriate sections).

Level 1: simply look at the absolute values of arterial $\mathrm{PO}_{2}, \mathrm{PCO}_{2}$, and $\mathrm{pH}$ compared to normal (allowing for the altitude at which measurements are made and age of the patient, which affect the normal range). Allowance for altitude can be performed by use of the alveolar gas equation (equation 8), first by inserting the correct inspired $\mathrm{PO}_{2}\left(\mathrm{PIO}_{2}\right)$ value for the particular altitude, and then inserting the actual arterial $\mathrm{PCO}_{2}$ of the patient). In the critically ill breathing gas higher than $21 \%$ in $\mathrm{O}_{2}$, analysis may include dividing arterial $\mathrm{PO}_{2}$ by inspired $\mathrm{O}_{2}$ concentration (to yield the $\mathrm{PaO}_{2} / \mathrm{FIO}_{2}$ ratio). This is an attempt to correct for $\mathrm{FIO}_{2}$ and is discussed below. Body temperature correction of all numbers should be performed before interpretation. Blood gas electrodes are almost always maintained and calibrated at $37^{\circ} \mathrm{C}$, and if a patient is febrile, in vivo $\mathrm{PO}_{2}$ and $\mathrm{PCO}_{2}$ will be higher than the reported values measured at $37^{\circ} \mathrm{C}$, and vice versa if the patient is hypothermic. Most analysers have inbuilt algorithms that correct for temperature automatically if the patient's temperature is entered, and it is these corrected values that should be used for interpretation, and especially in the alveolar gas equation for calculation of the $\mathrm{PA}_{-} \mathrm{aO}_{2}$ difference.

The outcomes of this level of analysis are simply to know whether $\mathrm{PO}_{2}$ is within the normal range (accounting for age, altitude, $\mathrm{FIO}_{2}$ and temperature), and similarly if $\mathrm{PCO}_{2}$ is low ( $<35 \mathrm{mmHg}$ ); normal (35-45 mmHg); or high ( $>45 \mathrm{mmHg}$ ). Figures 7 and 8 show how arterial $P_{\mathrm{O}_{2}}$ and the $\mathrm{PaO}_{2} / \mathrm{FIO}_{2}$ ratio behave over a range of values of $\mathrm{FIO}_{2}$ and with differing degrees of $V^{\prime} \mathrm{A} / Q^{\prime}$ inequality (fig. 7) and shunt (fig. 8). Note that while the two figures do differ systematically from each other, they show complexity such that major simplifications are difficult to achieve. They do show that mapping the variables over 

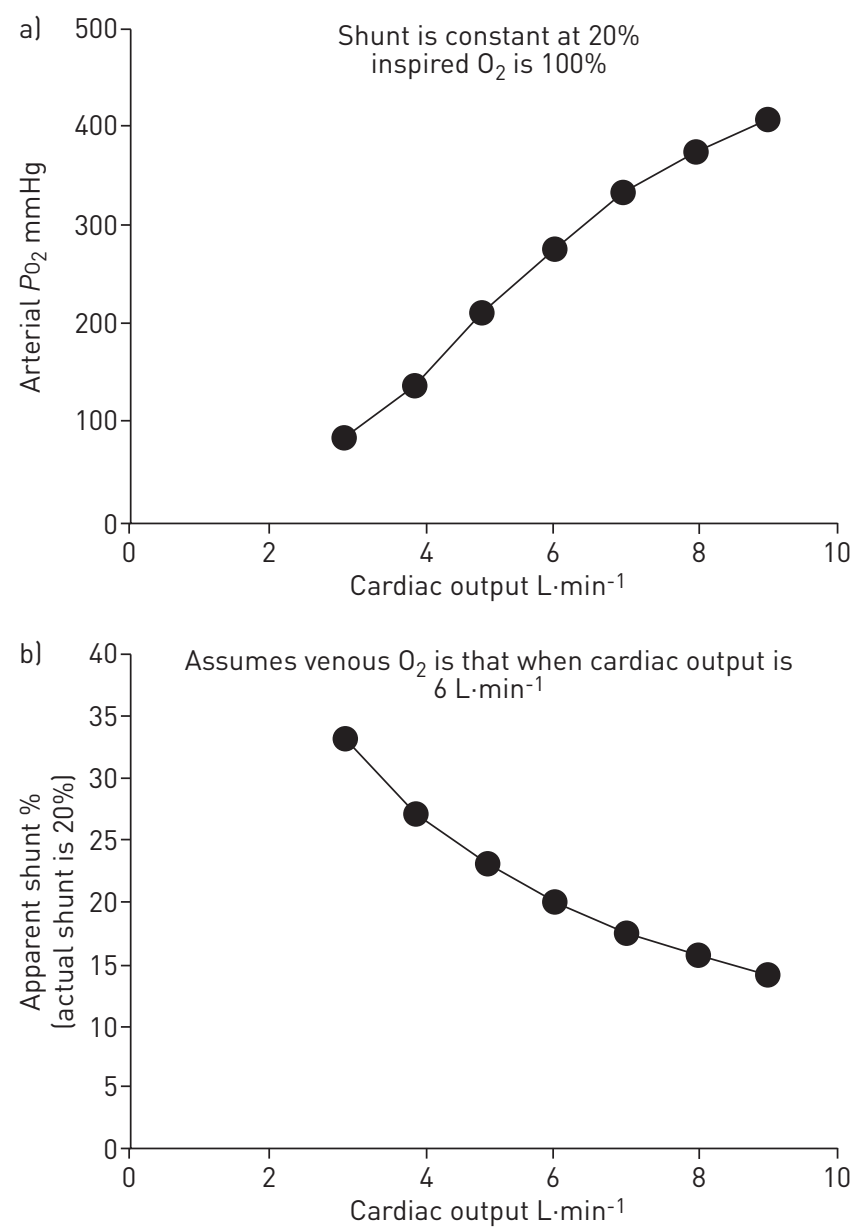

FIGURE 6 Simulation of a patient with a constant shunt of $20 \%$ of the cardiac output who is breathing $100 \% \mathrm{O}_{2}$. a) Arterial partial pressure of oxygen $\left(\mathrm{PO}_{2}\right)$ is very sensitive to cardiac output because as the latter falls, so must pulmonary arterial $\mathrm{PO}_{2}$ (perfusing the shunt pathway). This highlights the importance of accounting for differences in cardiac output from normal (here taken as $6 \mathrm{~L} \cdot \mathrm{min}^{-1}$ ). b) Apparent shunt computed in the same simulation from equation 11 based on arterial $\mathrm{PO}_{2}$ values in panel a when cardiac output is not normal (but is assumed to be normal). The true shunt may thus be over- or under-estimated considerably.

a range of $\mathrm{FIO}_{2}$ may be helpful in gaining a better understanding of the pathophysiology in individual patients, but this requires labour-intensive repeated arterial blood gas measurements at each $\mathrm{FIO}_{2}$ selected [20].

Level 2: calculate $\mathrm{PA}_{-a \mathrm{O}_{2}}$ from the alveolar gas equation (i.e. equation 8), using the measured arterial $\mathrm{PCO}_{2}$ $\left(P_{\mathrm{aCO}_{2}}\right)$ in place of alveolar $P_{\mathrm{CO}_{2}}\left(P_{\mathrm{ACO}_{2}}\right)$, and the respiratory exchange ratio $(\mathrm{R})$. If $\mathrm{R}$ is not measured, a reasonable value of $0.80-0.85$ can be assumed, but differences between assumed and actual $\mathrm{R}$ values can induce substantial errors in the $P \mathrm{~A}-\mathrm{aO}_{2}$ as the equation implies. For example, at normal arterial $P_{\mathrm{CO}_{2}}(40$ $\mathrm{mmHg}$ ) and $\mathrm{R}=0.8, \mathrm{PAO}_{2}$ would be $99 \mathrm{mmHg}$ (room air, sea level). However, if $\mathrm{R}$ were $0.7, \mathrm{PAO}_{2}$ would be $92 \mathrm{mmHg}$, and if $\mathrm{R}=1, P_{\mathrm{AO}_{2}}$ would be $109 \mathrm{mmHg}$.

Equation 8 yields the alveolar $\mathrm{PO}_{2}$ value, and all that needs to be done is to subtract the measured arterial $\mathrm{PO}_{2}$ to give $\mathrm{PA}_{\mathrm{A}-\mathrm{O}_{2}}$. In clinical circumstances, the exact form of the alveolar gas equation 9 is not necessary because the additional term in equation 9 is small, as substitution of normal values of $\mathrm{PaCO}_{2}$ and $\mathrm{R}$ in to equations 8 and 9 will show.

Breathing room air, $\mathrm{PA}_{\mathrm{A}-\mathrm{O}}$ is usually $5-10 \mathrm{mmHg}$ in young healthy subjects, but it increases a little with age to up to $20 \mathrm{mmHg}$ or so $[21,22]$. Unfortunately, $\mathrm{PA}_{\mathrm{a}} \mathrm{aO}_{2}$ is a noisy variable because it represents the usually small difference between two large numbers (alveolar and arterial $\mathrm{PO}_{2}$ ). Also, recall that it is based on steady state assumptions, as mentioned earlier, and so in a patient whose condition is rapidly changing, $P \mathrm{~A}-\mathrm{aO}_{2}$ will not be reliable.

What $P \mathrm{~A}-\mathrm{aO} \mathrm{O}_{2}$ provides over and above $\mathrm{PO}_{2}$ and $\mathrm{PCO}_{2}$ from level 1 analysis is the power to discriminate amongst some of the causes of hypoxaemia. Thus, if $\mathrm{PA}-\mathrm{aO}_{2}$ is normal yet there is hypoxaemia, one of the 

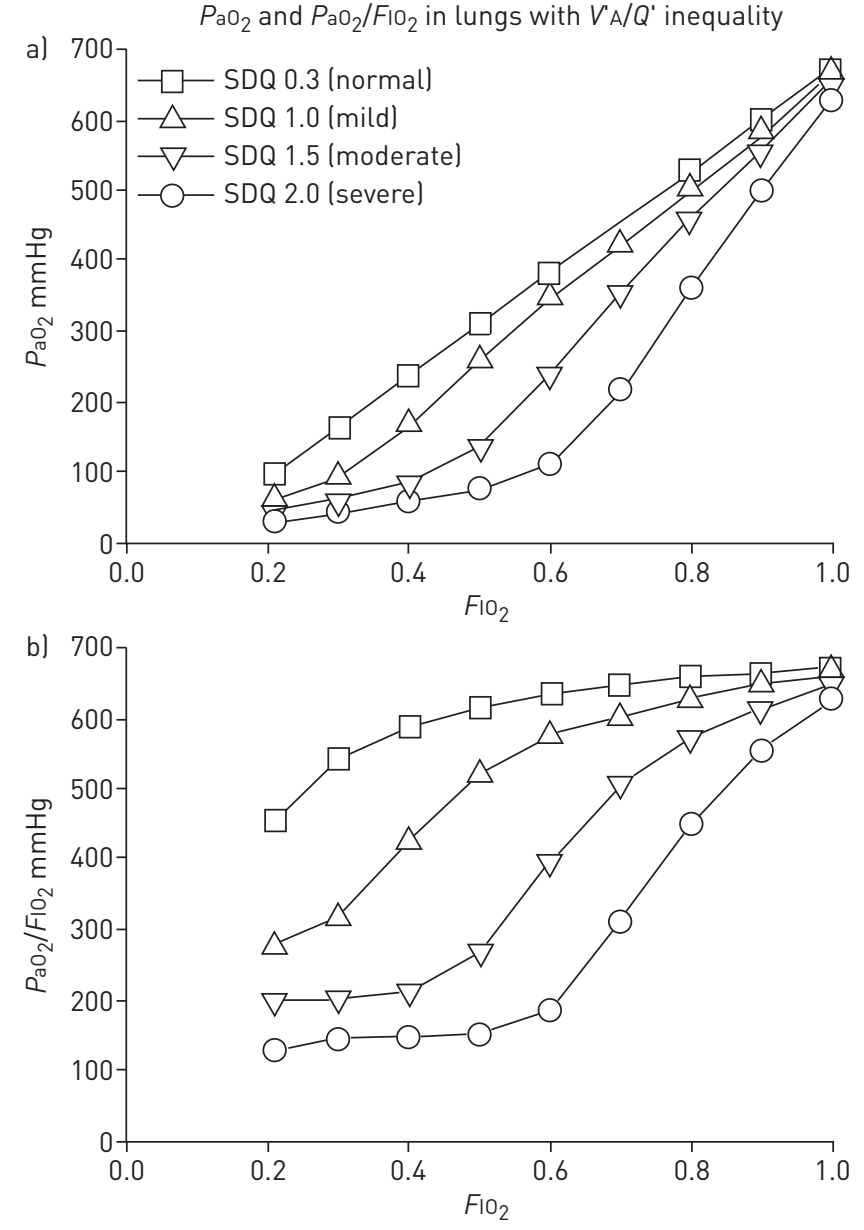

FIGURE 7 a) Arterial partial oxygen pressure $\left(\mathrm{PaO}_{2}\right)$ and b) $\mathrm{PaO}_{2}$ /inspired oxygen fraction $\left(\mathrm{FiO}_{2}\right)$ ratio as a function of $\mathrm{FIO}_{2}$ in lungs simulated to have only alveolar ventilation/perfusion $\left(V^{\prime} \mathrm{A} / Q^{\prime}\right)$ inequality and no shunt. Note that with moderate to severe inequality, $\mathrm{PaO}_{2} / \mathrm{FIO}_{2}$ is far from constant as $\mathrm{FIO}_{2}$ changes.

first two causes (reduced $\mathrm{PIO}_{2}$, hypoventilation, respectively) must be the explanation for the reduced arterial $\mathrm{PO}_{2}$. Distinguishing between the first two causes should be self-evident from knowing $\mathrm{FIO}_{2}$ and examining arterial $\mathrm{PCO}_{2}$, which is always elevated in cause 2, and usually reduced in cause 1 .

Examples are shown in figure 9a (for $V^{\prime} \mathrm{A} / Q^{\prime}$ inequality) and figure $10 \mathrm{a}$ (for shunt).

Level 3: calculate the physiological shunt $\left(Q_{s} / Q_{T}\right)$ and the physiological deadspace $\left(V_{D} / V_{T}\right)$, both defined below.

Qs/QT is a simple calculation that yields the percentage of total blood flow through the lungs that would have to be shunted (see shunt definition above) to explain the measured arterial $\mathrm{PO}_{2}$ on the assumption that the lungs can be simplified to a two-compartment system: one made up of alveoli that are all normally ventilated and perfused, and one that is perfused but not ventilated at all. The calculation uses mass conservation as follows:

$$
\mathrm{CaO}_{2} \times Q^{\prime} \mathrm{T}_{\mathrm{T}}=\mathrm{CiO}_{2} \times\left(Q^{\prime} \mathrm{T}-Q^{\prime} \mathrm{s}\right)+\mathrm{C}_{\overline{\mathrm{NO}}} \mathrm{O}_{2} \times Q^{\prime} \mathrm{S}
$$

Where $Q^{\prime} \mathrm{T}$ is total pulmonary blood flow, $Q^{\prime} \mathrm{s}$ is that portion of total flow passing through the vessels of the unventilated compartment (whose emerging blood $\mathrm{O}_{2}$ concentration remains that of the inflowing pulmonary arterial blood, $\mathrm{CrO}_{2}$ ), $\mathrm{CaO}_{2}$ is measured arterial $\mathrm{O}_{2}$ concentration, and $\mathrm{CiO}_{2}$ is the $\mathrm{O}_{2}$ concentration calculated, using the $\mathrm{HbO}_{2}$ dissociation curve, from the "ideal" $\mathrm{PO}_{2}$ or, in essence, the alveolar $\mathrm{PO}_{2}$ determined from equation 8. Rearranging, we get:

$$
Q S / Q T(\text { as a } \%)=100 \times\left(\mathrm{CiO}_{2}-\mathrm{CaO}_{2}\right) /\left(\mathrm{CiO}_{2}-\mathrm{C}_{\bar{v}}{ }_{2}\right)
$$




\section{$\mathrm{PaO}_{2}$ and $\mathrm{PaO}_{2} / \mathrm{FlO}_{2}$ in lungs with shunt}
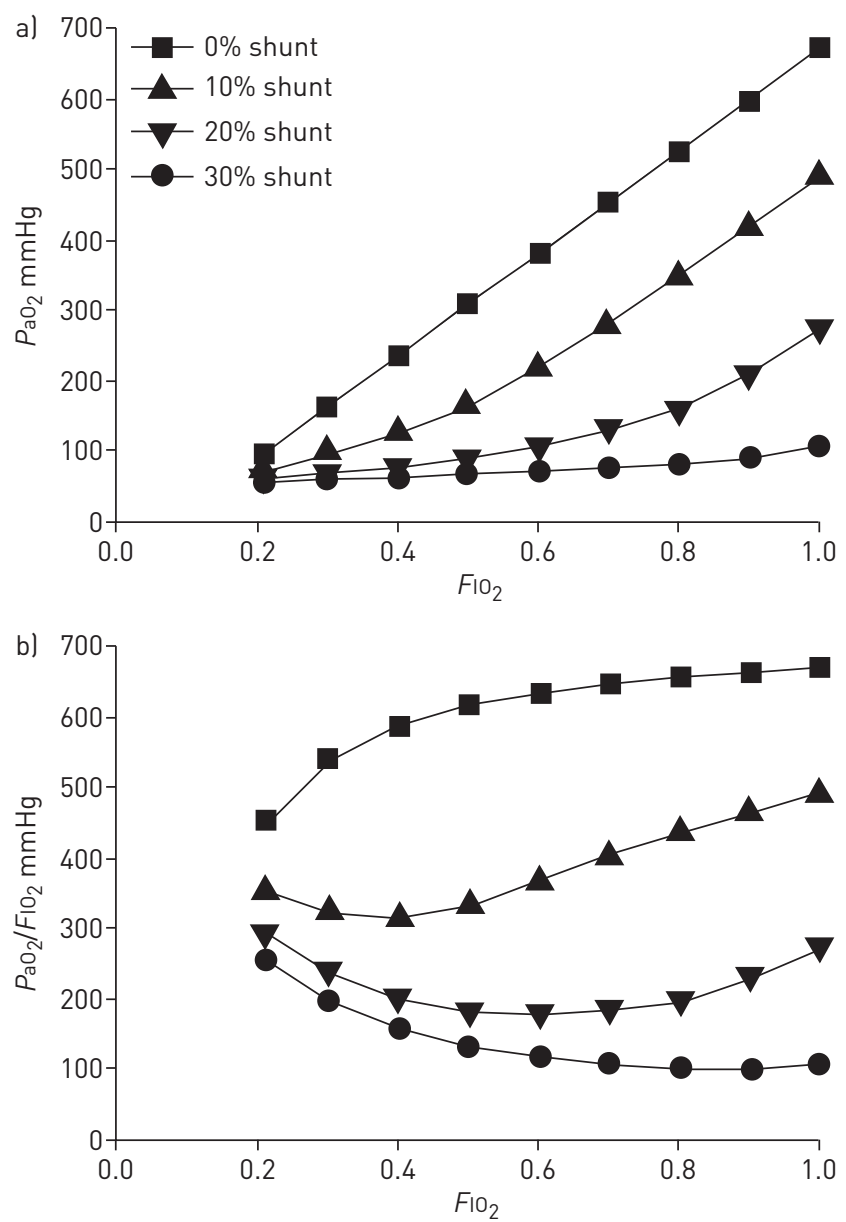

FIGURE 8 a) Arterial partial oxygen pressure $\left(\mathrm{PaO}_{2}\right)$ and b) $\mathrm{PaO}_{2}$ /inspired oxygen fraction $\left(\mathrm{FIO}_{2}\right)$ ratio as a function of $\mathrm{FIO}_{2}$ in lungs simulated to have only shunt and no alveolar ventilation/perfusion ratio inequality. $\mathrm{PaO}_{2} / \mathrm{FIO}_{2}$ steadily increases with $\mathrm{FIO}_{2}$ when shunt is absent or small, falls and then rises with $\mathrm{FIO}_{2}$ when shunt is moderate, and steadily falls when shunt is large.

Another form of this equation is:

$$
Q_{\mathrm{S}} / Q_{\mathrm{T}}=100 \times\left(\mathrm{CiO}_{2}-\mathrm{CaO}_{2}\right) /\left(\left(\mathrm{CiO}_{2}-\mathrm{CaO}_{2}\right)+\left(\mathrm{CaO}_{2}-\mathrm{CvO}_{2}\right)\right)
$$

Which from equation (2) can be rewritten as:

$$
Q \mathrm{~S} / Q_{\mathrm{T}}=100 \times\left(\mathrm{CiO}_{2}-\mathrm{CaO}_{2}\right) /\left(\left(\mathrm{CiO}_{2}-\mathrm{CaO}_{2}\right)+\left(0.1 \times V^{\prime} \mathrm{O}_{2} / Q^{\prime} \mathrm{T}\right)\right)
$$

Where $\mathrm{CiO}_{2}, \mathrm{CaO}_{2}$ and $\mathrm{CvO}_{2}$ are all in $\mathrm{mL} \cdot \mathrm{dL}^{-1}, V^{\prime} \mathrm{O}_{2}$ is in $\mathrm{mL} \cdot \mathrm{min}^{-1}$ and $\mathrm{Q}^{\prime} \mathrm{T}$ is in $\mathrm{L} \cdot \mathrm{min}^{-1}$. You will have to compute $\mathrm{CiO}_{2}$ and $\mathrm{CaO}_{2}$ from measured arterial blood gas values and saturation as follows:

$\mathrm{CiO}_{2}=1.39 \times[\mathrm{Hb}] \times$ fractional $\mathrm{O}_{2}$ saturation (calculated for the value of $\left.\mathrm{PAO}_{2}\right)+0.003 \times \mathrm{PAO}_{2}$

$\mathrm{CaO}_{2}=1.39 \times[\mathrm{Hb}] \times$ fractional $\mathrm{O}_{2}$ saturation (measured in arterial blood) $+0.003 \times \mathrm{PaO}_{2}$

Whether you choose to use equation 11 or equation 12 depends on whether you know $\mathrm{C}_{\overline{\mathrm{V}}} \mathrm{O}_{2}$ or alternatively $V^{\prime} \mathrm{O}_{2}$ and $Q^{\prime} \mathrm{T}$. If you know none of these variables, they will have to be assumed, which will result in uncertainty in the derived value of QS/QT [23].

The outcome, QS/QT, quantifies what may be called the virtual shunt. It is also called the physiological shunt, or sometimes, the venous admixture. At ambient $\mathrm{FIO}_{2}$, most commonly that of sea level room air, QS/QT may contain contributions from causes 3-6 when present: ventilation/perfusion inequality, diffusion limitation, and shunting plus the modulating effects of changes in the $V^{\prime} \mathrm{O}_{2} / Q^{\prime} \mathrm{T}$ relationship if present. It is not possible to separate these potential contributors just from looking at QS/QT itself, but the 

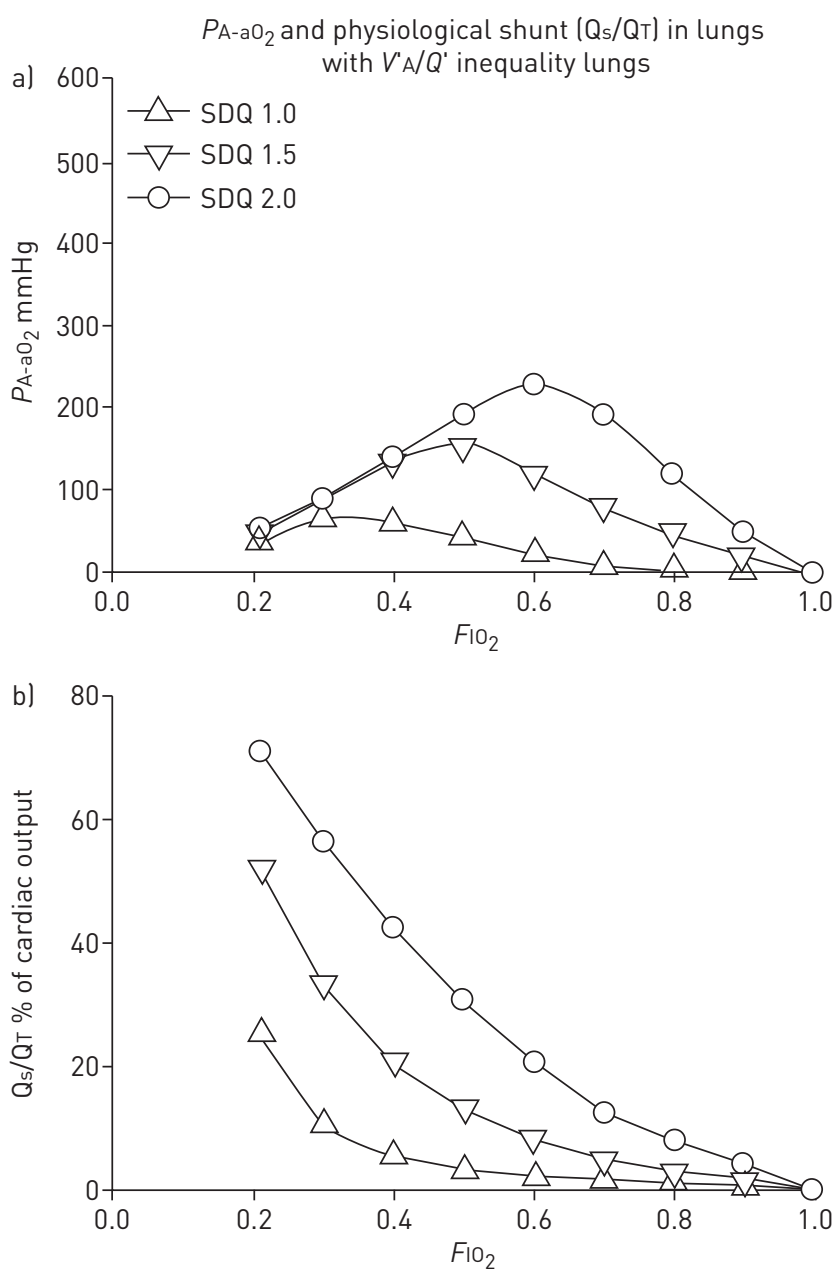

FIGURE 9 a) Alveolar-arterial oxygen partial pressure difference $\left(P_{\mathrm{A}-\mathrm{aO}_{2}}\right)$ and b) physiological shunt $\left(\mathrm{Qs}_{\mathrm{s}} / \mathrm{QT}\right)$ as a function of inspired oxygen fraction $\left(\mathrm{FIO}_{2}\right)$ in lungs simulated to have only alveolar ventilation/perfusion $\left(V^{\prime} \mathrm{A} / \mathrm{Q}^{\prime}\right)$ inequality and no shunt. $\mathrm{PA}_{\mathrm{A}-\mathrm{O}} \mathrm{O}_{2}$ peaks at intermediate $\mathrm{FIO}_{2}$ while physiological shunt steadily falls with increasing $\mathrm{FIO}_{2}$ in spite of constant amounts of inequality.

number obtained is a good overall index of the total gas exchange defect at the $\mathrm{FIO}_{2}$ experienced by the patient. Its utility beyond that of $\mathrm{PA}_{\mathrm{A}-\mathrm{aO}}$ is to quantify the gas exchange problem in terms of $\mathrm{O}_{2}$ concentration rather than partial pressure. $\mathrm{O}_{2}$ concentration is a better indicator of the effect on mass transport than is partial pressure, due to the nonlinear nature of the $\mathrm{HbO}_{2}$ dissociation curve. Qs/QT will not normally exceed $5 \%$ of the cardiac output from all causes combined.

Examples are shown in figure $9 \mathrm{~b}$ (for $V^{\prime} \mathrm{A} / Q^{\prime}$ inequality) and figure $10 \mathrm{~b}$ (for shunt).

$V \mathrm{D} / V \mathrm{~T}$ (physiological deadspace) is exactly analogous (and complementary) to QS/QT as follows. It represents a hypothetical $\mathrm{CO}_{2}$-free fraction of the total minute ventilation ( $V^{\prime} \mathrm{E}$, equation 1 ) that would have to be added to alveolar gas having a $\mathrm{PCO}_{2}$ equal to that measured in arterial blood in order to reach the measured $\mathrm{PCO}_{2}$ in mixed expired gas. Since the conducting airways (known as the deadspace) do not contribute to gas exchange, that $\mathrm{CO}_{2}$-free fraction is thought of as deadspace. The equation is as follows, very similar to that for QS/QT as it is also based on a two-compartment construct:

$$
V_{\mathrm{E}}^{\prime} \times P_{\mathrm{ECO}_{2}}=\left(V_{\mathrm{E}}^{\prime}-V_{\mathrm{D}}^{\prime}\right) \times P_{\mathrm{aCO}_{2}}+V_{\mathrm{D}}^{\prime} \times \text { zero }
$$

Where $\mathrm{PECO}_{2}$ is the $\mathrm{PCO}_{2}$ measured in mixed expired gas, $\mathrm{PaCO}_{2}$ is arterial $P \mathrm{CO}_{2}, V^{\prime} \mathrm{E}\left(\mathrm{L} \cdot \mathrm{min}^{-1}\right)$ is minute ventilation, and $V^{\prime} \mathrm{D}\left(\mathrm{L} \cdot \mathrm{min}^{-1}\right)$ is the ventilation associated with the virtual deadspace compartment $\left(\mathrm{PCO}_{2}\right.$ of zero). Rearranging equation 13 and multiplying by 100 to give the result as a percentage yields:

$$
V_{\mathrm{D}}^{\prime} / V_{\mathrm{E}}^{\prime}=100 \times\left(\mathrm{PaCO}_{2}-P \mathrm{ECO}_{2}\right) / \mathrm{PaCO}_{2}
$$


$P_{\mathrm{A}-\mathrm{aO}}$ and physiological shunt $\left(Q_{s} / Q_{T}\right)$ in lungs with shunt
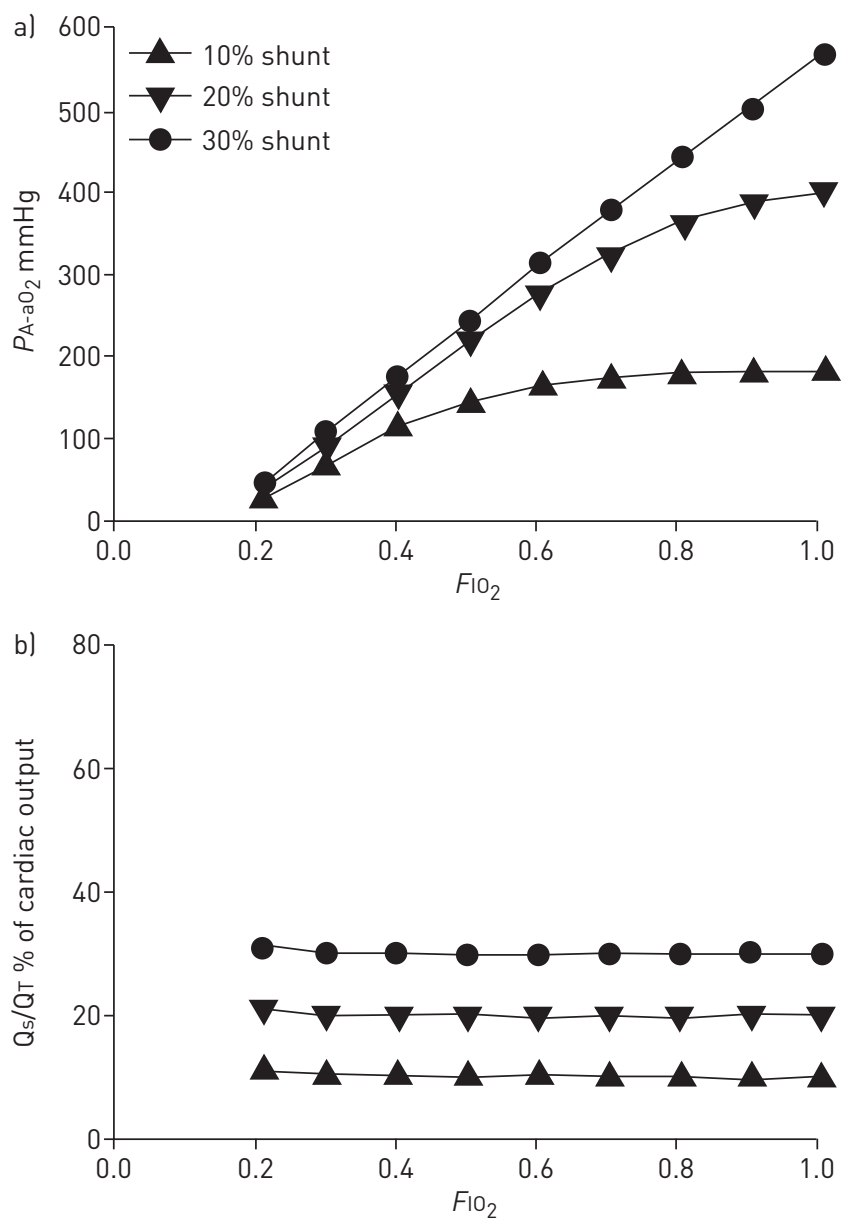

FIGURE 10 a) Alveolar-arterial oxygen partial pressure difference $\left(P_{\mathrm{A}-\mathrm{aO}}\right)$ and b) physiological shunt $\left(\mathrm{Qs}_{\mathrm{s}} / \mathrm{QT}_{\mathrm{T}}\right)$ as a function of inspired oxygen fraction $\left(\mathrm{FIO}_{2}\right)$ in lungs simulated to have only shunt and no alveolar ventilation/perfusion inequality. Arterial $\mathrm{PO}_{2}$ steadily rises but calculated shunt remains constant as $\mathrm{FIO}_{2}$ is raised.

More commonly, $V^{\prime} \mathrm{E}$ is renamed $V \mathrm{~T}$ in this equation, yielding the familiar term " $V \mathrm{D} / V \mathrm{~T}$ ". Unlike $Q S / Q \mathrm{~T}$, the normal value of which is near zero, the absence of gas exchange in the 17 or so generations of the conducting airways of the lung (airways which total about $150 \mathrm{~mL}$ in volume) [24] contribute substantially to $V \mathrm{D} / V \mathrm{~T}$. The tidal volume (volume of each breath) is about $500 \mathrm{~mL}$ at rest, and so $V \mathrm{D} / V \mathrm{~T}$ is normally $150 / 500$ or $30 \%$. Unfortunately, changes in tidal volume will have a major effect on $V \mathrm{D} / V \mathrm{~T}$. If a subject dropped tidal volume to $400 \mathrm{~mL}, V \mathrm{D} / V \mathrm{~T}$ would now become $150 / 400$ or $38 \%$. An exercising subject with a $2 \mathrm{~L}$ tidal volume will have a $V \mathrm{D} / V \mathrm{~T}$ of $150 / 2000$, or just $8 \%$.

It is therefore recommended to multiply $V \mathrm{D} / V_{\mathrm{T}}$ by actual tidal volume and estimate $V \mathrm{D}$ in $\mathrm{mL}$ per breath, which normally should approximate $150 \mathrm{~mL}$, whatever the tidal volume. Then, any increase in $V \mathrm{D}$ above $150 \mathrm{~mL}$ per breath (i.e. $V \mathrm{D}-150$ ) likely denotes an alveolar gas exchange abnormality typified by development of areas of increased $V^{\prime} \mathrm{A} / Q^{\prime}$ ratio. Any such increase in $V D$ is interpreted as a virtual defect; alveoli considered as being ventilated but not perfused, with a volume per breath equal to $V D$ (as measured) less $150 \mathrm{~mL}$. It should also be remembered that the volume of the conducting airways ( $150 \mathrm{~mL}$ in the preceding) varies with body size, and using $2 \mathrm{~mL} \cdot \mathrm{kg}^{-1}$ in subjects with normal BMI is reasonable [25]. In very obese subjects, one should probably use $2 \mathrm{~mL} \cdot \mathrm{kg}^{-1}$ lean body mass.

Note that in addition to the arterial blood gas measurement of $\mathrm{PCO}_{2}$, one needs to collect and measure $\mathrm{PCO}_{2}$ in mixed expired gas $\left(\mathrm{EECO}_{2}\right)$, and measure tidal volume (either directly or by measuring $V^{\prime} \mathrm{E}$ and dividing by respiratory frequency). Sometimes, the end-tidal $\mathrm{PCO}_{2}$ is measured rather than the arterial, with the assumption that they are the same. This is reasonable in health but may be quite incorrect in disease, where end-tidal $\mathrm{PCO}_{2}$ may exceed arterial $\mathrm{PCO}_{2}$, due to 1) continuing addition of $\mathrm{CO}_{2}$ to alveolar gas during expiration, and 2) more poorly ventilated regions with higher than average $\mathrm{PCO}_{2}$ emptying later in each breath. Finally, the mixed expired $\mathrm{PCO}_{2}$ can be computed from rapid analysis of exhaled $\mathrm{CO}_{2}$ 
Table 1 brings all of these concepts together in summary form. It is wise to remember, however, that summary tables, such as this, depict usual or common situations, and that to every rule there can be an exception. In particular, the interaction between any of the listed causes of hypoxaemia and ventilatory responsiveness of the subject plays a large role in the blood gas picture seen in an individual, explaining why the arterial $\mathrm{PCO}_{2}$ can be elevated, reduced or normal in many settings.

\section{Summary}

While gas exchange in the lungs follows straightforward principles which are well understood, assessment of the severity and nature of gas exchange disturbances in patients can be complicated, and in particular, requires not just arterial blood gas data, but a defined set of ancillary variables in order to properly separate the many causes and modifying factors that combine to ultimately set arterial $P_{2} /$ $\mathrm{PCO}_{2}$. While this article provides some tools to enable such analysis, the practitioner has to decide in each case whether the greater understanding afforded by these ancillary measurements is justified by clinical need.

\section{References}

1 Wagner PD, Laravuso RB, Uhl RR, et al. Continuous distributions of ventilation-perfusion ratios in normal subjects breathing air and $100 \% \mathrm{O}_{2}$. J Clin Invest 1974; 54: 54-68.

2 West JB. Ventilation/Bloodflow and Gas Exchange. Oxford, Blackwell, 1970.

3 Wagner PD, West JB. Effects of diffusion impairment on $\mathrm{O}_{2}$ and $\mathrm{CO}_{2}$ time courses in pulmonary capillaries. $J$ Appl Physiol 1972; 33: 62-71.

4 Rahn H, Fenn WO. A Graphical Analysis of the Respiratory Gas Exchange. Washington, American Physiological Society, 1955.

5 Riley RL, Cournand A. "Ideal" alveolar air and the analysis of ventilation/perfusion relationships in the lung. $J$ Appl Physiol 1949; 1: 825-847.

6 Riley RL, Cournand A, Donald KW. Analysis of factors affecting partial pressures of oxygen and carbon dioxide in gas and blood of lungs: methods. J Appl Physiol 1951; 4: 102-120.

7 Riley RL, Cournand A. Analysis of factors affecting partial pressures of oxygen and carbon dioxide in gas and blood of lungs: theory. J Appl Physiol 1951; 4: 77-101.

8 Dubois $\mathrm{AB}$. Alveolar $\mathrm{CO}_{2}$ and $\mathrm{O}_{2}$ during breath holding, expiration, and inspiration. J Appl Physiol 1952; 5: 1-12.

9 West JB. Ventilation/perfusion inequality and overall gas exchange in computer models of the lung. Respir Physiol 1969; 7: 88-110.

10 Piiper J, Scheid P. Model for capillary-alveolar equilibration with special reference to $\mathrm{O}_{2}$ uptake in hypoxia. Respir Physiol 1981; 46: 193-208.

11 Wagner PD, Gale GE, Moon RE, et al. Pulmonary gas exchange in humans exercising at sea level and simulated altitude. J Appl Physiol 1986; 61: 260-270.

12 West JB, Wagner PD. Predicted gas exchange on the summit of Mt. Everest. Respir Physiol 1980; 42: 1-16.

13 Agustí AGN, Roca J, Gea J, et al. Mechanisms of gas exchange impairment in idiopathic pulmonary fibrosis. Am Rev Respir Dis 1991; 143: 219-225.

14 Rodriguez-Roisin R, Krowka MJ. Hepatopulmonary syndrome-A liver-induced lung vascular disorder. $N$ Engl J Med 2008; 358: 2378-2387.

15 Wagner PD, Dantzker DR, Dueck R, et al. Ventilation-perfusion inequality in chronic obstructive pulmonary disease. J Clin Invest 1977; 59: 203-216.

16 Wagner PD, Dantzker DR, Iacovoni VE, et al. Ventilation-perfusion inequality in asymptomatic asthma. Am Rev Respir Dis 1978; 118: 511-524.

17 Kapitan KS, Buchbinder M, Wagner PD, et al. Mechanisms of hypoxemia in chronic thromboembolic pulmonary hypertension. Am Rev Respir Dis 1989; 139: 1149-1154.

18 West JB, Wagner PD. Pulmonary gas exchange. In: West JB, ed. Bioengineering Aspects of the Lung. New York, Marcel Dekker, Inc., 1977; pp. 361-458.

19 Lemaire F, Harf A, Teisseire BP. Oxygen exchange across the acutely injured lung. In: Zapol WM, Falke KJ, eds. Acute Respiratory Failure. New York, Dekker, 1985; pp. 521-552.

20 Villar J, Perez-Mendez L, Blanco J, et al. A universal definition of ARDS: the $\mathrm{PaO}_{2} / \mathrm{FiO}_{2}$ ratio under a standard ventilatory setting-a prospective, multicenter validation study. Intensive Care Med 2013; 39: 583-592.

21 Raine JM, Bishop JM. A-a difference in $\mathrm{O}_{2}$ tension and physiological dead space in normal man. J Appl Physiol 1963; 18: 284-288.

22 Cardús J, Burgos F, Diaz O, et al. Increase in pulmonary ventilation/perfusion inequality with age in healthy individuals. Am J Respir Crit Care Med 1997; 156: 648-653.

23 Wagner PD. Recent Advances in Pulmonary Gas Exchange. International Anesthesiology Clinics. 15th edn. Boston, Little Brown \& Co., 1977; pp. 81-111.

24 Weibel ER. Morphometry of The Human Lung. Berlin/New York, Springer-Verlag, 1963.

25 Fowler WS. Lung function studies. II. The respiratory dead space. Am J Physiol 1948; 154: 405-416.

26 Vogiatzis I, Athanasopoulos D, Boushel R, et al. Contribution of respiratory muscle blood flow to exercise-induced diaphragmatic fatigue in trained cyclists. J Physiol 2008; 586: 5575-5587.

27 Nunn JF, Bergman NA, Bunatyan A, et al. Temperature coefficients for $\mathrm{PCO}_{2}$ and $\mathrm{PO}_{2}$ of blood in vitro. J Appl Physiol 1965; 20: 23-26. 